\title{
Tamoxifen - no longer a golden standard for adjuvant therapy in the treatment of premenopausal patients with hormone-sensitive breast cancer
}

\author{
Renata Duchnowska
}

For several decades, in breast cancer patients with a luminal subtype, tamoxifen has been the main endocrine therapy in adjuvant setting in both pre- and postmenopausal women. However, it may be suboptimal in some premenopausal patients. The results of prospective, randomised studies SOFT/TEXT clearly demonstrated that the combination of OFS with TAM or IA is more effective than monotherapy TAM in breast cancer premenopausal women with hormonesensitive early breast cancer and a high risk of recurrence.

NOWOTWORY J Oncol 2016; 66, 5: 415-417

Key words: tamoxifen, aromatase inhibitor, ovarian function suppression, breast cancer, premenopausal women

\section{Introduction}

Luminal breast cancer (with the expression of the oestrogen (ER) and/or progesterone PR receptor) makes up a heterogenous group of cancer with a varied clinical course and response to treatment. Currently there are three molecular subtypes of luminal breast cancer and the subtypes which are similar to them, determined on the basis of the reception of the steroid receptors and human epidermal growth factor receptor type 2 (HER2): Iuminal A, luminal B HER2-negative and luminal B - HER2-positive [1, 2]. Within these subtypes there are also mutations found e.g. phosphoinositide-3 kinase catalytic subunits p110; (PIK3CA), ESR 1 or $H E R 2$, which can determine the response to treatment, [3-5]. For a few decades, hormone therapy with tamoxifen (TAM) has been the main method of the adjuvant treatment of the luminal subtype in both pre- and postmenopausal women [2, 6-9]. It seems, however, that the treatment might be suboptimal in some premenopausal patients.

Special attention in the debate on the treatment of breast cancer in premenopausal women is devoted to the role of ovarian function suppression (OFS). The analysis, published in year the 2000 concerning research in this issue, carried out by the International Breast Cancer Study Group (IBCSG) showed that in patients with ER/PR expression without amenorrhea with a history of previous adjuvant chemotherapy, the prognosis of the disease free survival (DFS) and overall survival, (OS) is significantly worse in the age subgroup below 35 years in comparison with patients older than 35 [10]. Some further studies also showed that apart from the age of the patients, the percentage of amenorrhea is also affected by the type of chemotherapy used: the regimens based on anthracyclines and taxoids more rarely lead to a permanent suppression of the ovarian function in comparison with the CMF (cyclophosphamide/methotrexate/fluorouracil) regimen [11]. Moreover, it was shown that in patients below 35, the ER expression, in comparison with the lack of expression, was related to a significantly shorter 10 -year DFS (the median was $25 \%$ and $47 \%$ respectively; $p=0.014$ ) and a tendency for a shorter OS; whilst in patients above this age, the ER expression had no influence on DFS, but it was connected with a significantly longer 10-year OS (63\% and 58\% respectively; $\mathrm{p}<0.001)$ [12]. 


\section{Ovarian function suppression in tamoxifen therapy}

In the phase-3 prospective SOFT (Suppression of Ovarian Function Trial) trial the premenopausal patients with ER/PR expression, with no history of post-surgical chemotherapy or in whom the oestradiol level after chemotherapy corresponded to that from before the menopause, received tamoxifen or tamoxifen in combination with OFS (LHRH analogue for 5 years) [13]. Adding the OFS did not affect DFS ( $H R=0.83$; $p=0.1$ ) in the entire group of patients, whilst the analysis with stratification, planned in the treatment protocol showed that adding OFS to tamoxifen in the subgroup of patients undergoing postoperative chemotherapy was connected with a decrease of the relative risk of morality by as much as $36 \%$. Given the fact that breast cancer is the most frequent cancer in women worldwide, it means a decrease of the number of deaths by several thousand per year. In the SOFT study, the adjuvant chemotherapy was more often used in patients below 35 years of age (94\%), and, at the same time, in this group, treatment-related amenorrhoea was less frequent. The adjuvant chemotherapy was also used in the case of numerous ( $\geq 4$ ) metastases to axillary lymph nodes and HER2 expression. The benefits from adding OFS, in DFS and OS, was not observed in the subgroup of patients with good prognoses, similarly to another phase-3 trial (INT-0142) [14]. In this group of patients, TAM still remains the standard post-operative treatment with a possibility of extending the treatment to 10 years, in the light of the ATLAS and aTTom studies $[15,16]$. On the other hand, however, in premenopausal patients, the potential benefit from prolonged use of TAM should be interpreted with caution, as this group of patients made up only $13 \%$ of the total number of patients treated within the studies comparing varied periods of using TAM [15-17]. Irrespective of individual differences in the pharmacokinetics of TAM, about $20 \%$ of patients treated with this medication did not reach the treatment threshold of endoxifen - its main active metabolite [18-20].

\section{Aromatase inhibitors in connection with ovarian function suppression}

The joint analysis of SOFT and TEXT (Tamoxifen and Exemestane Trial) studies showed that OFS (mainly LHRH analogue, triptorelin administered for 5 years) in combination with exemestane, aromatase inhibitor (IA) in comparison with OFS in combination with TAM, allows an improvement in the 5 -year DFS (91\% and $87 \%$ respectively; $p<0.001)$, a decrease of the relative risk of breast cancer recurrence by $34 \%(p<0.001)$ and cancer dissemination by $22 \%(p=0.02)$, with a similar survival period [21]. The treatment with OFS in combination with IA was more frequently associated with adverse symptoms, yet they did not cause deterioration in the quality of life, especially in patients with previous postoperative chemotherapy [22]. Moreover, the intensification of menopausal symptoms - hot flushes or decrease of libido, was getting lower within the progress of time since the onset of treatment $[22,23]$. No symptoms concerning the incomplete blockage of oestrogen levels in patients with OFS/IA were observed [24]. In the majority of cases, the oestradiol level was lowered below the threshold value for menopause: $2.72 \mathrm{pg} / \mathrm{mL}$ [24].

Those who question the value of the SOFT and TEXT trials for clinical practice, frequently refer to the result of the ABCSG-12 study, carried out in Austria, in which no benefits regarding DFS were found $[25,26]$. Moreover, in some cases even slightly worse OS was observed in patients receiving OFS in combination with anastrozole in comparison with OFS in combination with TAM $[25,26]$. However, in the ABCSG-12 study, about $70 \%$ of the subjects were in a very early stage - pT1N0, which confirms that, in this group, the use of OFS in combination with IA is completely not justified.

\section{Conclusions}

The results of the prospective randomised studies, SOFT/ /TEXT explicitly showed that the combination of OFS with TAM or IA is more effective than TAM in monotherapy in premenopausal patients with hormone-sensitive breast cancer with a high risk of recurrence. This justifies a routine use of the OFS treatment regimes in this group of patients, with maintenance of the TAM therapy in the patients with good prognosis. This thesis was reflected in the recommendations of the St. Gallen 2015 Conference of the European Society of Medical Oncology and of the National Comprehensive Cancer Network $[6,9,28]$. The decision concerning the choice of hormone treatment in breast cancer patients should be taken on an individual basis after a detailed discussion of the potential benefits and possible adverse effects of this therapy (Tab. I) [8, 29].

Table I. Hormone therapy in premenopausal patients

\begin{tabular}{|c|c|c|c|c|}
\hline \multicolumn{5}{|c|}{ Premenopausal patients } \\
\hline Age & $\leq 3$ & & & \\
\hline \multirow[t]{2}{*}{ Low risk of recurrence ${ }^{1}$} & \multicolumn{4}{|c|}{ TAM 5-10 years ${ }^{2}$} \\
\hline & \multicolumn{4}{|c|}{ Approval of the adverse effects risk } \\
\hline \multirow[t]{2}{*}{ High risk of recurrence } & Yes & No & Yes & No \\
\hline & OFS/TAM lub OFS/IA 3 & TAM & OFS/IA & TAM \\
\hline
\end{tabular}

${ }^{1} \mathrm{pT}, \mathrm{N}, \mathrm{G}, \mathrm{HER} 2$ characteristics, OncotypeDx; ${ }^{2}$ contraindications for TAM $\rightarrow$ OFS (LHRH analogue) \pm IA; TAM — tamoxifen; IA — aromatase inhibitors; OFS - ovarian suppression; ${ }^{3}$ the presentation of the adverse effects profile to the patient 
Conflict of interest: none declared

\author{
Renata Duchnowska, MD, PhD \\ Department of Oncology \\ Military Institute of Medicine \\ Szaserów 128, 04-141 Warszawa, Poland \\ e-mail: rdtt@wp.pl
}

Received \& Accepted: 9 May 2016

Based on the presentation at the IV Annual Conference of the Nowotwory Journal of Oncology, 'Oncological Debates', held in Warszawa, 8-9th April 2016

\section{References}

1. Perou CM, Sørlie T, Eisen MB et al. Molecular portraits of human breast tumours. Nature 2000; 406: 747-752.

2. Goldhirsch A, Winer EP, Coates AS et al. Personalizing the treatment of women with early breast cancer: highlights of the St. Gallen International Expert Consensus on the Primary Therapy of Early Breast Cancer 2013. Ann Oncol 2013; 24: 2206-2223.

3. Creighton CJ, Fu X, Hennessy BT et al. Proteomic and transcriptomic profiling reveals a link between the PI3K pathway and lower estrogen-receptor (ER) levels and activity in ER+ breast cancer. Breast Cancer Res 2010; 12: R40.

4. Cancer Genome Atlas Network. Comprehensive molecular portraits of human breast tumours. Nature 2012; 490: 61-70.

5. Jeselsohn R, Buchwalter G, De Angelis C et al. ESR1 mutations a mechanism for acquired endocrine resistance in breast cancer. Nat Rev Clin Oncol 2015; 12: 573-583.

6. Coates AS, Winer EP, Goldhirsch $A$ et al. Tailoring therapies-improving the management of early breast cancer: St. Gallen International Expert Consensus on the Primary Therapy of Early Breast Cancer 2015. Ann Oncol 2015; 26: 1533-1546.

7. Cardoso F, Costa A, Norton L et al. ESO-ESMO 2nd international consensus guidelines for advanced breast cancer (ABC2). Ann Oncol 2014; 25: 1871-1888.

8. Jassem J, Krzakowski M. Rak piersi. In: Zalecenia postępowania diagnostyczno-terapeutycznego w nowotworach złośliwych 2013 rok. Gdańsk: Via Medica, 2013, 211-265.

9. www.ncen.org.

10. Aebi S, Gelber S, Castiglione-Gertsch M et al. Is chemotherapy alone adequate for young women with oestrogen-receptor-positive breast cancer? Lancet 2000; 355: 1869-1874.

11. Goodwin PJ, Ennis M, Pritchard Kl et al. Risk of menopause during the first year after breast cancer diagnosis. J Clin Oncol 1999; 17: 2365-2370.

12. Goldhirsch A, Gelber RD, Yothers $G$ et al. Adjuvant therapy for very young women with breast cancer: need for tailored treatments. J Natl Cancer Inst Monogr 2001; 2001: 44-51.

13. Francis PA, Regan MM, Fleming GF et al. Adjuvant ovarian suppression in premenopausal breast cancer. N Engl J Med 2015; 372: 436-446.

14. Tevaarwerk AJ, Wang $M, Z$ Zhao F et al. Phase III comparison of tamoxifen versus tamoxifen plus ovarian function suppression in premenopausal women with node-negative, hormone receptor-positive breast cancer (E-3193, INT-0142): a trial of the Eastern Cooperative Oncology Group. J Clin Oncol 2014; 32: 3948-3958.

15. Davies C, Pan H, Godwin J et al. Long-term effects of continuing adjuvant tamoxifen to 10 years versus stopping at 5 years after diagnosis of oestrogen receptor-positive breast cancer: ATLAS, a randomised trial. Lancet 2013; 381: 805-816. Erratum in: Lancet 2013; 381: 804.

16. Gray RG, Rea D, Handley D et al. aTTom: Long-term effects of continuing adjuvant tamoxifen to 10 years versus stopping at 5 years in 6,953 women with early breast cancer. J Clin Oncol 2013; 31 (Suppl; abstr 5).

17. Al-Mubarak M, Tibau A, Templeton AJ et al. Extended adjuvant tamoxifen for early breast cancer: a meta-analysis. PLoS One 2014; 9: e88238.

18. Madlensky L, Natarajan L, Tchu S et al. Tamoxifen metabolite concentrations, CYP2D6 genotype, and breast cancer outcomes. Clin Pharmacol Ther 2011; 89: 718-725.

19. Jager NG, Rosing $\mathrm{H}$, Schellens JH et al. Tamoxifen dose and serum concentrations of tamoxifen and six of its metabolites in routine clinical outpatient care. Breast Cancer Res Treat 2014; 143: 477-483.

20. Hennig EE, Piatkowska M, Karczmarski J et al. Limited predictive value of achieving beneficial plasma (Z)-endoxifen threshold level by CYP2D6 genotyping in tamoxifen-treated Polish women with breast cancer. BMC Cancer 2015; 15: 570.

21. Pagani O, Regan MM, Walley BA et al. Adjuvant exemestane with ovarian suppression in premenopausal breast cancer. $N$ Engl J Med 2014; 371: 107-118.

22. Bernhard J, Luo W, Ribi K et al. Patient-reported outcomes with adjuvant exemestane versus tamoxifen in premenopausal women with early breast cancer undergoing ovarian suppression (TEXT and SOFT): a combined analysis of two phase 3 randomised trials. Lancet Oncol 2015; 16: 848-858.

23. Ribi K, LuoW, Bernhard J et al. Adjuvant tamoxifen plus ovarian function suppression versus tamoxifen alone in premenopausal women with early breast cancer: patient-reported outcomes in the suppression of ovarian function trial. J Clin Oncol 2016; 34: 1601-1610.

24. Bellet M, Gray KP, Francis PA et al. Twelve-month estrogen levels in premenopausal women with hormone receptor-positive breast cancer receiving adjuvant triptorelin plus exemestane or tamoxifen in the suppression of ovarian function trial (SOFT): The SOFT-EST Substudy. J Clin Oncol 2016; 34: 1584-1593.

25. Gnant M, Mlineritsch B, Schippinger W et al. Endocrine therapy plus zoledronic acid in premenopausal breast cancer. N Engl J Med 2009; 360: 679-691.

26. Gnant $\mathrm{M}$, Mlineritsch B, Stoeger $\mathrm{H}$ et al. Zoledronic acid combined with adjuvant endocrine therapy of tamoxifen versus anastrozol plus ovarian function suppression in premenopausal early breast cancer: final analysis of the Austrian Breast and Colorectal Cancer Study Group Trial 12. Ann Oncol 2015; 26: 313-320.

27. Early Breast Cancer Trialists' Collaborative Group (EBCTCG), Dowsett M, Forbes JF, Bradley R et al. Aromatase inhibitors versus tamoxifen in early breast cancer: patient-level meta-analysis of the randomized trials. Lancet 2015 ; 386: 1341-1352.

28. Senkus E, Kyriakides S, Ohno S et al. Primary breast cancer: ESMO Clinical Practice Guidelines for diagnosis, treatment and follow-up. Ann Oncol 2015; 26 Suppl 5: v8-v30.

29. Jassem J, Krzakowski M (eds). Rak piersi: Praktyczny przewodnik dla lekarzy. Wyd. 2. Gdańsk: Via Medica, 2014. 